\title{
PEDAGOGIZAR CORPOS E CONFORMAR SUBJETIVIDADES: O SINTAGMA IDEOLOGIA DE GÊNERO COMO EXERCÍCIO COLONIZADOR DA EDUCAÇÃO
}

\author{
Carlos Magno Camargos MENDONÇA \\ Universidade Federal de Minas Gerais - UFMG \\ Belo Horizonte, Minas Gerais - Brasil \\ macomendonca@gmail.com \\ http://orcid.org/0000-0002-4883-3410
}

Felipe Viero Kolinski Machado MENDONÇA Universidade Federal de Ouro Preto - UFOP

Mariana, Minas Gerais - Brasil felipeviero@gmail.com http://orcid.org/0000-0002-8051-126X

\begin{abstract}
Resumo: No intuito de ponderar sobre a primordialidade da existência dos conteúdos que abordam questões de gênero, de educação sexual e de sexualidade nos currículos escolares, este ensaio ampliado indaga como a implementação da agenda de combate ao gênero, proposta por setores conservadores, referenda uma pauta de exclusões e violências. Supomos que extinguir tais temas dos currículos escolares e das políticas de formação docente busca perpetuar atos de dominação e opressão masculina, além de reduzir a capacidade crítica de docentes e discentes. Nossa argumentação ampara-se na aproximação dos estudos comunicacionais aos estudos de gênero e estudos culturais.
\end{abstract}

Palavras-Chave: Ideologia de gênero; educação; masculinidades.

\section{PEDAGOGIZE BODIES AND CONFORM SUBJECTIVITIES: THE SYNTAGM GENDER IDEOLOGY AS A COLONIZING EXERCISE IN EDUCATION}

\begin{abstract}
In order to reflect on the primacy of the existence of content that addresses issues of gender, sex education and sexuality in school curricula, this expanded essay asks how the implementation of the agenda to combat gender, proposed by conservative sectors, endorses an agenda of exclusions and violence. We assume that extinguishing such themes from school curricula and teacher training policies
\end{abstract}




\section{autêntica}

DOI https://doi.org/10.31639/rbpfp.v12i24.338

seeks to perpetuate acts of male domination and oppression, in addition to reducing the critical capacity of teachers and students. Our argument is based on the approach of communicational studies to gender studies and cultural studies.

Key words: Gender ideology; education; masculinities.

\section{PEDAGOGIZAR CUERPOS Y CONFORMAR SUBJETIVIDADES: EL SINTAGMA IDEOLOGÍA DE GÉNERO COMO UN EJERCICIO COLONIZADOR EN EDUCACIÓN}

Resumen: Para reflexionar sobre la primacía de la existencia de contenido que aborda cuestiones de género, sexualidad y sexualidad en los planes de estudio escolares, este ensayo ampliado pregunta cómo la implementación de la agenda para combatir el género, propuesta por sectores conservadores, respalda una agenda de exclusiones y violencia. Suponemos que la extinción de tales temas de los planes de estudio escolares y las políticas de capacitación docente busca perpetuar los actos de dominación y opresión masculina, además de reducir la capacidad crítica de maestros y estudiantes. Nuestro argumento se basa en el enfoque de los estudios comunicacionales para los estudios de género y los estudios culturales.

Palabras-clave: Ideología de género; Educación; Masculinidades 


\title{
autêntica
}

DOI https://doi.org/10.31639/rbpfp.v12i24.338

\section{Introdução}

\begin{abstract}
(...) um currículo nunca é neutro: desde a seleção dos conteúdos, autores/as, materiais didáticos, perspectivas teórico-metodológicas etc., tudo opera em torno da produção de sentidos e de relações de poder. Nesses termos, pensar em currículos de formação docente que contemplem gênero e sexualidade como questões importantes é uma operação ética, política, pedagógica e institucional atravessada por disputas e tensionamentos (FELIX, 2015, p. 226).
\end{abstract}

A partir de uma apropriação efetuada pelos Estudos em Comunicação de elementos oriundos dos Estudos de Gênero e Estudos Cultuais, este ensaio ampliado problematiza alguns aspectos da agenda de combate ao gênero impetrada por setores conservadores da sociedade brasileira. Para tanto, temos como base para a nossa argumentação dados consequentes das pesquisas que desenvolvemos juntos aos Programas de Pós-Graduação em Comunicação da Universidade Federal de Minas Gerais e da Universidade Federal de Ouro Preto. Partimos do pressuposto de que a negação dos direitos sexuais corresponde à negação de direitos humanos, a perpetuação de desigualdades, a manutenção da hierarquia dos poderes, a divisão social do trabalho e a dominação do feminino pelo masculino. Diante do exposto, consideramos a necessidade da presença dos conteúdos que debatem gênero, educação sexual e sexualidade nos currículos escolares, na formação docente, bem como na conversação entre os e as agentes da comunidade escolar. Entendemos que os processos de formação docente, tal como os conteúdos neles abordados, repercutem de modo ampliado no projeto educacional de um país. Seja na formação inicial, os cursos de licenciatura, ou na formação continuada, aquela que se faz a par e passo às mutações do ambiente escolar, acreditamos que as questões de gênero devam estimular perguntas e reflexões. O alicerce para a geração de conhecimento, seja para docentes ou discentes, é a vida socialmente partilhada. Docentes, tal como todos os outros agentes, estão inseridos em uma estrutural social, estão expostas e expostos às mudanças nas vivências em sociedade. Os conhecimentos adquiridos na formação inicial não se atualizarão por inércia. A formação continuada é uma necessidade constante na docência, tanto para que docentes percebam as limitações e possibilidades do projeto educacional do qual participam quanto para compreenderem a si, os seus desejos, os seus valores, os seus saberes diante das situações experimentadas no ambiente da comunidade escolar. Apostamos que uma oportuna formação continuada dos e das docentes repercute sobre a escola e sobre as pessoas que a ela estão de alguma maneira interligados. A formação docente continuada favorece o fortalecimento ético para docentes e discentes.

Nossa hipótese é que a agenda de combate ao gênero, ao perceber o ambiente escolar como solo fértil para a divulgação de seus valores, executa um movimento de negar/afirmar a importância da formação no ambiente escolar. O valor de reconhecimento é revelado na intensidade do ataque aos programas e projetos que objetivam o estabelecimento de uma perspectiva crítica. Entendo a masculinidade como subtema no campo dos estudos de gênero, acreditamos que a agenda conservadora atua para barrar a discussão crítica tanto na busca da extinção do conteúdo no currículo escolar quanto na formação docente. Ensaiamos, aqui, alguns aspectos que assinalam a importância de debater, nos mais diferentes níveis de formação educacional, a masculinidade e seus efeitos. Sob o arqueamento educação/formação humana, acreditamos que este debate, nos mais diferentes níveis de formação, contribui para encerrar um ciclo de exclusões e violência, bem como reduzir a capacidade crítica de docentes e discentes. Esta hipótese sustenta-se sobre três axiomas, a saber. Axioma 1: os chamados combatentes do gênero estão imantados por uma crença no determinismo biológico dos corpos. Logo, uma vez definido o gênero pelo sexo do nascimento, seria natural os modos pelos quais ocorrem a organização e a hierarquização social, as vivência nos espaços públicos e privados, os papéis sociais desenvolvidos por homens e mulheres. Axioma 2: na agenda de combate ao gênero o 


\section{autêntica}

DOI https://doi.org/10.31639/rbpfp.v12i24.338

masculino está posicionado no vértice da pirâmide social, estando abaixo dele todos os demais agentes sociais. Nessa perspectiva, o masculino possui um sentido fechado, universal e materializado em corpos com pênis. Entretanto, é preciso ressaltar que a construção da hegemonia masculina não oferece uniformidade à masculinidade. Portanto, devemos sempre tratar o termo no plural e entender que as masculinidades se manifestam sobre corpos de homens e mulheres. Axioma 3: as masculinidades são constituídas socialmente e não atribuídas biologicamente. Isto quer dizer que elas não são uma consequência biológica da evolução humana, sendo, assim, passíveis de serem analisadas e questionadas; as masculinidades compreendem um sem número de performances de gênero e atuações sociais.

Nosso percurso argumentativo está divido em três partes. Na primeira parte, retomamos um julgamento recente, efetuado pelo Supremo Tribunal Federal, sobre a constitucionalidade de uma lei municipal que determinava a retirada de conteúdos disciplinares e materiais didáticos que abordassem gênero e educação sexual na escola. O julgamento é o artífice para tecer algumas considerações sobre a chamada "ideologia de gênero" e rever alguns comportamentos dos combatentes do gênero. Na segunda parte, olhamos para dados relativos ao ambiente escolar(oriundos do Censo Escolar INEP) com vistas a perceber como a organização sexual do trabalho (BIROLI, 2018; CONNELL, 2015) dispõe os quadros docentes e discentes nas escolas brasileiras. Na última parte, debatemos como determinada masculinidade investe nos processos de invisibilização social, no combate à conquista de direitos, na redução da consciência de classe, na diminuição do racismo e na opressão dos corpos via a ampliação dos discursos de ódio.

\section{Ideologia de gênero: um sintagma}

No dia 29 de abril de 2020, o Supremo Tribunal Federal (STF) julgou inconstitucional a Lei 1.516/2015, do município de Novo Gama, Goiás, que proibia a utilização em escolas públicas de material didático daquilo que na Lei era denominado "ideologia de gênero". O Plenário seguiu o voto do relator, ministro Alexandre de Moraes. O relator considerou que compete à União a edição de normas que orientem os currículos, os conteúdos programáticos, as metodologias de ensino e as formas de atividade docente. Sem nos alongarmos na íntegra do voto, destacamos aqui dois pontos do texto. O primeiro deles: "ao aderir à imposição do silêncio, da censura e, de modo mais abrangente, do obscurantismo como estratégias discursivas dominantes, de modo a enfraquecer ainda mais a fronteira entre a heteronormatividade e homofobia" estaria a lei municipal em desacordo com um princípio e um dos objetivos fundamentais da Constituição Cidadã - a promoção da igualdade, através do desenvolvimento de políticas de inclusão. O segundo ponto: o ministro avançou em sua considerações ponderando que a referida lei acentuava condições de discriminação baseadas na identidade de gênero e orientação sexual'.

Segundo o professor e pesquisador Rogério Diniz Junqueira (2018), o termo ideologia de gênero apareceu pela primeira vez na nota chamada "A ideologia de gênero: seus perigos e seus alcances", emitida pela Conferência Episcopal do Peru, no ano de 1994. Por meio de uma pesquisa em documentos eclesiásticos, textos religiosos e laicos, o pesquisador perseguiu os caminhos fundadores do sintagma "ideologia de gênero" e do projeto de poder que daí surgiu e se ampliou. É interessante notar que ao utilizar o significante sintagma Junqueira (2018) associa à "ideologia de gênero" o significado, ou mesmo uma relação de reconhecimento, de algo composto ao modo de uma trama. Ou seja, há um conjunto de elementos inseridos na tessitura do sentido, enredados na unidade significativa que valora o termo. A trama possui relações hierárquicas e de interdependência. Nos termos de Junqueira (2018) o referido sintagma opera sob a forma de um aparato retórico e persuasivo. Como um aparato retórico, há um apelo à audiência nos três níveis da Retórica: logos, pathos e ethos. 


\section{autêntica}

DOI https://doi.org/10.31639/rbpfp.v12i24.338

O primeiro nível, logos, tenta apresentar um argumento racional para o conteúdo do discurso. O argumento defende uma tese. A potência dos argumentos reduzem a capacidade de refutação da tese. Para tanto, no caso em questão, há a invocação de uma ou mais formas de conhecimento científico para validar o sentido pretendido. Sob esta curvatura estão abrigadas a (re)biologização e (re)naturalização essencialista dos corpos, por exemplo. Entretanto, é preciso lembrar o componente religioso nesse nível, uma invocação da razão divina - o orador fala inspirado pelo divino. No sintagma "ideologia de gênero" este componente precede a todos. O segundo nível, pathos, é o produtor da empatia. Este nível opera diretamente sobre as emoções do público. A persuasão está amparada na comoção produzida pelo discursos e na identificação do público com o orador - nós como pais de família estamos preocupados com a sua família, com a integridade de todas as famílias, por exemplo. Na situação aqui em foco, a identificação não é apenas das ideias, ela se expressa nos corpos, nas maneiras pelas quais estes dão-se a ver e correspondem a certas formas de representação. Tais formas direcionam a concepção de bom e ruim para os corpos e para a descrição de si; de correto e de incorreto diante de valores (hetero)sexistas; daquilo que se deve desejar e do desejo do qual se deva afastar; dentre outras muitas estratégias sensíveis de colonização dos corpos e pensamentos. No terceiro nível, ethos, há o convencimento pela autoridade do orador. Na circunstância em pauta, há uma propagação de comportamentos, costumes e hábitos a serem cultivados. Orientados por uma moral conservadora, os hábitos estão sob as regras previstas nas normas de gênero. A hierarquização do masculino sobre o feminino; a determinação de que o homem é o responsável pela conduta moral da família; a preservação de um modelo familiar único e religiosamente orientado; a submissão da mulher ao homem; a crença na correlação direta entre sexo biológico e comportamento social; são alguns dos operadores éticos deste nível.

Junqueira (2018, s/p) considera o apelo retórico o giro para uma agenda moralmente planejada e regressiva, claramente destinada a conter avanços nos debates sobre gênero, sexo e sexualidade, "além de reafirmar disposições tradicionalistas, pontos doutrinais dogmáticos e princípios religiosos 'não negociáveis'". Se compreendemos a ofensiva conservadora como um exercício de mobilização política e discursiva, tal como proposto por Junqueira (2018), a perceberemos como uma ação planejada estrategicamente; com previsão de investimentos econômicos, financeiros e simbólicos; com fronteiras determinadas a serem conquistas. Para o êxito de tal investida, a conformação dos hábitos serve-se de investidas discursivas na esfera pública, ocupações de postos políticos e intervenção nos espaços educacionais. A supressão dos estudos de gêneros, dos debates sobre sexualidade, da educação sexual no ambiente escolar reflete o intuito de privar adolescentes de acessarem informações sobre saúde sexual e desenvolvimento da sexualidade, manter a hierarquização dos corpos, bem como propagar desigualdades frente a qualquer diversidade. Remontando mais uma vez ao trabalho de Junqueira (2018) é meta desta cruzada, desta agenda antigênero, separar direitos sexuais de direitos humanos ou mesmo negar os direitos sexuais em favor de hierarquias de gênero historicamente estabelecidas.

Apesar da agenda antigênero ser organizada sob diferentes aspectos temporais, territoriais e socioculturais, os polemistas de gênero, sublinha Junqueira (2018), desenham a imagem do inimigo com traços comuns: feministas, ativistas LGBTs, "esquerdistas comunistas", com ou sem partidos políticos. Estes conjuntos de sujeitos, na perspectiva alarmista dos combatentes do gênero, criam procedimentos de sujeição travestidos de luta por liberdade e encontram no ambiente escolar o terreno fecundo para plantar sua ideologia.

Não por acaso, o campo da Educação está entre os que recebem atenção prioritária desses movimentos, e parece ser onde eles têm encontrado mais facilidade para obstruir propostas inclusivas, antidiscriminatórias, voltadas a valorizar a laicidade, o pluralismo, a promover o reconhecimento da diferença e a garantir o caráter público e cidadão da formação escolar. Tais propostas são 


\title{
autêntica
}

DOI https://doi.org/10.31639/rbpfp.v12i24.338

\begin{abstract}
denunciadas como "ameaça à liberdade de expressão, crença e consciência" das famílias, cujos valores morais e religiosos seriam inconciliáveis com as normativas sobre direitos humanos, impostas por governos e organismos internacionais. Escolas e docentes sintonizados com a "ideologia de gênero" visariam usurpar dos paiso protagonismo na educação moral e sexual de crianças e adolescentes para instilar-Ihes a propaganda gender e doutriná-los conforme crenças e valores de um sistema de "pensamento único", hermético, deliberadamente ambíguo, sedutor, enganoso, danoso e manipulador da natureza humana. (JUNQUEIRA, 2018, s/p)
\end{abstract}

No Brasil, como no restante do mundo, os combatentes do gênero investiram fortemente na agenda política, com grande impacto no campo educacional. O debate entorno de um projeto denominado escola sem partido e sem discussão de gênero colocou em destaque no cenário político nacional figuras como o deputado Pastor Marco Feliciano, o senador Magno Malta, a atual ministra da Mulher, Família e Direitos Humanos, Damares Alves, além de impulsionar o deputado Jair Bolsonaro à cadeira de mandatário da nação. Para todas estas personagens o texto é comum: existe uma orquestração contra a família, promovida por uma esquerda marxista. Surgido em 2004, animado pelo ex-procurador paulista Miguel Nagib, o movimento "Escola sem Partido" propõe uma neutralidade política no ambiente escolar. Para isso, os professores devem evitar a expressão de posicionamentos políticos, sob a pena de serem acusados de exercerem doutrinações, as escolas não devem estimular estudantes à participação política. Nessa perspectiva, estaria rejeitada qualquer discussão sobre gênero, seja na formação de docentes, seja na formação dos discentes.

No ano de 2014, o então deputado estadual Flávio Bolsonaro convidou Miguel Nagib para redigir um Projeto de Lei (PL 29/74) a ser apresentado para a Assembleia Legislativa do Rio de Janeiro. Simultaneamente, o vereador Carlos Bolsonaro apresentou um semelhante Projeto de Lei (864/2014) para a Câmara Municipal da Cidade do Rio de Janeiro. Ambos projetos tornaram-se inspiração para outras Câmaras Municipais e Assembleias Legislativas. Em 2015, a discussão chegou ao Congresso Nacional através do Projeto de Lei 867/2015. Os projetos de lei elaborados a partir dos valores do movimento Escola sem Partido têm em comum os seguintes pontos: as crenças familiares sobre educação moral, religiosa e sexual possuem prevalência sobre qualquer conteúdo previsto no currículo escolar. Em decorrência deste primeiro item, está vetada a participação do poder público no chamado "amadurecimento sexual de estudantes". É dever do poder público combater os exercícios de doutrinação efetuados pelas e pelos docente. Portanto, é dever do Estado propiciar canais de denuncias de tais fatos. É proibido ao professor ou professora expressarem seus valores políticos, suas crenças religiosas ou morais, sob o risco de serem acusados de propagandistas político/partidários. Estão proibidos e banidos termos como "gênero" ou "orientação sexual". Todas as escolas deveriam exibir cartazes contendo os deveres dos e das professoras.

\section{O gênero e a instituição escolar}

O sintagma "ideologia de gênero" tem por convicção uma continuidade linear entre sexo/gênero/sexualidade (LOURO, 2008). Por meio de uma naturalização essencialistas dos corpos e comportamentos, nessa lógica teríamos: macho - fêmea / homem - mulher/ heterossexual. Lembramos que naturalizar é a primeira forma para não debater ou mesmo para esvaziar o debate de alguma questão. O recurso retórico à naturalização do gênero e dos papéis de gênero objetiva perpetuar mecanismos de dominação masculina. Por consequência, fazem durar formas de exclusão de todos os corpos que estejam fora desta linha formada pela continuidade entre sexo, gênero e sexualidade. Na disputa discursiva implementada pelo alarmistas do gênero, há a desvalorização dos saberes que se dedicam a coligar direitos sexuais e direitos humanos, a buscar igualdade de gênero, a criar uma visão crítica sobre luta de classes, a denunciar o racismo, a valorizar as diversidades 


\section{autêntica}

DOI https://doi.org/10.31639/rbpfp.v12i24.338

existenciais. Ao atuarem sobre os projetos educacionais, sejam eles desenvolvidos pela esferas municipal, estadual ou federal, os combatentes do gênero investem não apenas na supressão destes saberes, mas também no fim da formação docente destinada a estes temas. Guiados por valores religiosos que entendem gênero e sexualidade à luz de uma compreensão moral, o que fazem os defensores da escola sem partido e sem gênero é reificar uma "ideologia de gênero" que, sendo exclusivamente cis-heteronormativa, tutela corpos e designa, pedagogicamente, a ascendência do masculino sobre o feminino, os valores do patriarcado como base para a organização familiar e social, a subalternidade de todos os corpos não homem.

Eleito com um discurso conservador, o governo Jair Bolsonaro é reconhecido por seus posicionamentos ultraconservadores. Sua gestão, esvaziada de propostas e projetos para as políticas públicas sociais, educacionais e de saúde, tem por marca os retrocessos moralistas, as ações públicas orientada por valores dogmáticos e a negação do pensamento científico. Na área da educação a gestão é caracterizada pelo boicote às pesquisas educacionais, sociais e psicológicas, dentre outras que versam sobre o tema, sob a égide de pertencerem ao pensamento de esquerda e terem fins políticos catequizadores. Em substituição, há abertura para o pensamento religioso neopentecostal como guia moral do aprendizado, para a educação no ambiente familiar em detrimento do espaço escolar, para a desvalorização do educador crítico. A ministra da Mulher, Família e Direitos Humanos não se furta a afirmar a superioridade masculina, a posicionar a mulher como cuidadora do lar e a entender a família como supervisora da educação moral e sexual de crianças e adolescentes. É fato que a visão dogmática de todo o governo está amparada na crença da superioridade masculina. Para tanto, a supressão dos conteúdos curriculares que versam sobre gênero e educação sexual e, por consequência, o não investimento na formação docente para atuarem nestes campos de saber servem à manutenção das estruturas hierárquicas e excludentes secularmente construídas. Uma estrutura se faz por repetição rotineira no tempo e no espaço. As atuais políticas governamentais usam antigas estruturas que separam e rejeitam pessoas para a construção de hegemonias masculinas. O resultado de tudo isto é a criação de um tipo de vulnerabilidade estatal, responsável por precarizar ainda mais a existência de corpos femininos, efeminados ou divergentes das masculinidades dominantes.

A educadora e pesquisadora Jeane Felix, ao refletir sobre questões de gênero e formação docente, cunha uma definição a seguinte definição para a noção gênero:

Compreendo gênero como um elemento organizador do social (MEYER, 2003). Com isso, quero dizer que os espaços por onde circulamos, as instituições em que trabalhos, as relações nas quais estamos inseridas e inseridos se constituem a partir do gênero que, por sua vez, tem funcionado, por um lado, a favor, ou, por outro, "como modo de resistir à naturalização de regimes de verdade que apontam um lugar 'natural' e fixo para cada gênero" (VASCONCELOS e SEFFNER, 2015) e, assim, para os sujeitos de gênero, individual e coletivamente. Gênero, nessa direção, é pensado e compreendido a partir de alguns de seus desdobramentos teóricos e políticos. Tais desdobramentos, na perspectiva apresentada por Dagmar Meyer (2003, pp. 16-18), são: somos constituídos como sujeitos de gênero, ao longo de nossa vida, por meio das diferentes instituições e práticas sociais; existem múltiplas e conflitantes formas de definir e viver as feminilidades e masculinidades; gênero não diz respeito apenas às mulheres, mas às relações de poder entre homens e mulheres, mulheres e mulheres, homens e homens; a perspectiva de gênero não se reduz aos papeis e funções sociais de mulheres e homens e, sim, considera que instituições sociais, símbolos, normas, conhecimentos, leis "são constituídas e atravessadas por representações e pressupostos de feminino e de masculino, ao mesmo tempo em que estão centralmente implicadas com sua produção, manutenção ou ressignificação" (p. 18) (FELIX, 2015, 224)².

2 As e os autores citados por Felix na noção aqui transcritas constam das referências bibliográficas. 


\section{autêntica}

A professora e pesquisadora Guacira Lopes Louro (1997), em obra sobre gênero, sexualidade e educação, lembra que ao se compreender que o gênero institui a identidade do sujeito constata-se que se está falando de algo que transcenderia o mero desempenho de um papel social. Tal qual pondera Judith Butler (2019), ainda que nossas identidades plurais também sejam constituídas a partir de outros marcadores (envolvendo aspectos étnico-raciais, econômicos e geográficos, por exemplo) nos tornamos inteligíveis pelo gênero com o qual nos identificam. E essa identificação, é importante ressaltar, não raras vezes ocorre antes mesmo de nascermos ou, no mais tardar, no momento em que o fazemos e, a plenos pulmões, com uma frase, um plano é instituído para nós. As declarações "é uma menina" ou "é um menino" instauram um processo que, supostamente, deveria ter um rumo definido. Tais frases, mais do que dizer, fazem dos corpos que nomeiam masculinos e femininos, conferindo a determinadas características biológicas o poder de gerar diferenças. "O ato de nomear o corpo acontece no interior de uma lógica que supõe o sexo como um "dado" anterior à cultura e Ihe atribui um caráter imutável, a-histórico e binário" (LOURO, 2008, p. 17).

Por trás da questão "é um menino ou é uma menina?", "esconde-se um sistema diferenciado que fixa a ordem empírica tornando o corpo inteligível graças à fragmentação ou dissecação dos órgãos" (PRECIADO, 2014, p. 128). A tecnologia sexual, então, seria uma mesa de operações abstrata a qual delimitaria determinadas zonas corporais como sendo sexuais (pênis e vagina) ao passo que negaria a outras essa condição.

Sob tal lógica, continuará Louro (1997, p. 25), torna-se flagrante que "diferentes instituições e práticas sociais são constituídas pelos gêneros e são, também, constituintes dos gêneros". Depreende-se daí que o governo, que a justiça, que a mídia e que, também, as práticas educativas, por exemplo, são instâncias generificadas, ou seja, engendram-se a partir de relações de gênero e, ao contribuírem para a constituição de sujeitos, também o fazem com base nesses lugares específicos. Forjam gêneros e, em movimentos cíclicos, são forjadas por eles.

Mas, nesse cenário, qual seria então o gênero da escola? A pergunta lançada por Louro (1997, p. 88), muito interessante, a partir de prismas diversos, traz respostas diametralmente opostas. "Ora, respondem imediatamente alguns/as, a escola é feminina, porque é, primordialmente, um lugar de atuação de mulheres". Em sendo uma atividade assinalada pelo cuidado para com o outro, pela vigilância em relação a um comportamento adequado e pelo ensino, a docência tende a ser tomada como uma atividade "essencialmente" feminina.

Essa tal "essência feminina" então evocada, é mister pontuar, consiste em um reflexo daquilo que se compreende como um padrão de comportamento feminino que deve se dar no espaço doméstico e, por conseguinte, ter continuidade no espectro profissional. Diversos discursos pedagógicos, advindos tanto de matrizes teóricas, quanto da legislação, sugerem que, tal qual relações familiares, as práticas escolares, idealmente, deveriam ser pautadas pelo afeto, pela confiança e pela conquista do interesse da criança e/ou do adolescente (LOURO, 1997).

O Censo Escolar da Educação Básica de 2018, realizado pelo Instituto Nacional de Estudos e Pesquisas Educacionais Anísio Teixeira (Inep), revelou um dado importante: uma em cada três disciplinas é lecionada por docente sem formação específica. Este dado varia de acordo com o nível da escolaridade e a região do país. Segundo o documento ${ }^{3}$, o quadro se agrava no ensino fundamental e, em especial, nos anos iniciais. O documento revela outro dado valoroso: $81,44 \%$ das matrículas pertence às escolas públicas. $O$ ensino público detém, também, a maior parte dos mais de 2,5 milhões de professoras e professores em exercício 


\section{autêntica}

DOI https://doi.org/10.31639/rbpfp.v12i24.338

no Brasil. Dentre os 2,2 milhões de docentes dedicados à educação básica, $80 \%$ são do sexo feminino. Deste total, metade das professores tem 40 anos ou mais.

Os dados do Censo Escolar evidenciam a divisão sexual do trabalho no ensino (BIROLI, 2018; CONNELL, 2015). No Brasil replica-se a ideia comum em tantos outros países: a educação de crianças e de pré-adolescentes é uma função das mulheres. $O$ ato de atribuir para o sexo feminino a responsabilidade de educar figura uma extensão das responsabilidades da maternidade. A ocupação masculina cresce no ensino médio e superior. Sob a ótica da divisão sexual do trabalho, é interessante notar que estes níveis de ensino exigem outras capacidades e especializações, muitas delas caracterizadas como próprias ao masculino e que, cabe ressaltar, acarretam em maiores dividendos materiais (salários) e simbólicos.

Desde o século XIX, observa Louro (1997), é possível identificar no Brasil diferentes transformações sociais que permitiram o ingresso de mulheres nas salas de aula, então na condição de discentes, e, pouco a pouco, colaboraram para que o magistério, então "feminizado", se consolidasse como uma profissão tipicamente voltada a elas.

"Os discursos que se constituem pela construção da ordem e do progresso, pela modernização da sociedade, pela higienização da família e pela formação dos jovens cidadãos implicam a educação das mulheres" mas, mais que isso, das futuras mães (LOURO, 1997, p. 96). Em sendo, naquele contexto, o casamento, a maternidade e os cuidados para com o marido e com os filhos as tarefas femininas fundamentais, qualquer atividade profissional seria, pois, considerada um desvio. A alternativa, aí, seria transpor tais práticas do espaço doméstico, e privado, para o espaço profissional, e coletivo. Essa feminização do magistério, tal qual fala Louro (1997), dá-se a partir de um movimento que pega de empréstimo atributos culturalmente designados como femininos, tais como o amor, a sensibilidade e o cuidado e os compreende como estruturantes da carreira na educação.

Em contrapartida, por outro lado, poder-se-ia dizer que, na verdade, a escola seria um espaço masculino. "Ao contrário, dizem outras/os, a escola é masculina, pois ali se lida, fundamentalmente, com o conhecimento - e esse conhecimento foi historicamente produzido pelos homens" (LOURO, 1997, p. 89). Ao não tratar de qualquer conhecimento, mas de dado conhecimento que foi selecionado, reconhecido e autorizado, a escola aproxima-se, portanto, de uma série de características que se compreendem, em uma lógica binária, como sendo masculinas. "É possível argumentar que, ainda que as agentes do ensino possam ser mulheres, elas se ocupam de um universo marcadamente masculino - não apenas porque as diferentes disciplinas escolares se construíram pela ótica dos homens, mas porque a seleção, a produção e a transmissão dos conhecimentos [...] são masculinos" (LOURO, 1997, p. 89).

Mais do que a delimitação de qual alternativa seria a mais acertada, Louro (1997, p. 89) sugerirá que a verdadeira potência do questionamento reside no fato dele explicitar o quão generificado é o ambiente escolar. "O que fica evidente, sem dúvida, é que a escola é atravessada pelos gêneros; é impossível pensar sobre a instituição sem que se lance mão das reflexões sobre as construções sociais e culturais de masculino e feminino".

Dentre as informações trazidas pelo censo da educação básica de 2019, divulgadas nesse ano de 2020, há pouco sobre questões de gênero. O dado mais específico, então localizado, sinaliza que, dentre os cerca de 600 mil docentes da educação infantil, os quase um milhão e meio que atuam no ensino fundamental e os pouco mais de 500 mil do ensino médio, cerca de $80 \%$ são mulheres. 


\section{autêntica}

DOI https://doi.org/10.31639/rbpfp.v12i24.338

Em parceria com o portal IEDE (Interdisciplinaridade e Evidências no Debate Educacional), que trabalha com a divulgação de pesquisas sobre educação, o Porvir, plataforma de conteúdos e mobilização sobre inovações educacionais do Brasil, apresentou um interessante levantamento sobre trajetórias estudantis de meninos e de meninas e, ainda, sobre questões de gênero em relação à docência ${ }^{4}$.

Em se tratando da docência, há diferenças abissais entre a presença de professores e de professoras na educação infantil, básica e superior. Em relação à educação infantil, segundo dados trazidos, há, no país, quase 554 mil professoras e apenas 21.310 professores. Na educação básica, as mulheres seguem sendo maioria: são 1.758 .94 professoras e 437.425 professores. A situação inverte-se, justamente, em relação ao ensino superior, onde exige-se uma maior formação e, ainda, onde existem as melhores remunerações: nesse contexto, existem cerca de 210 mil professores e quase 175.000 professoras.

Em relação ao gênero, também na condição de discentes, algumas informações são igualmente interessantes de serem recuperadas. Embora tanto meninos quanto meninas apresentem desempenho abaixo do esperado ao final da educação básica, constata-se que meninas alcançam melhores avalições em leitura e resolução colaborativa de problemas ao passo que meninos obtêm melhores resultados em matemática e ciências.

Sobre aptidão, comportamento e confiança, os dados também indicam lugares distintos aos estudantes homens e às estudantes mulheres. Ao passo que $75 \%$ das meninas responderam que leem por prazer, em relação aos meninos esse número ficou em 50\%; $20 \%$ dos meninos responderam que jogam videogame diariamente. Em relação às meninas esse número é de $2 \%$. Ainda que meninos estudem, em média, por semana, uma hora a menos do que as meninas e ainda que 6 em cada 10 alunos que não atingiram o nível básico de proficiência em português, matemática e ciências fossem meninos, quatro vezes mais meninos que meninas intencionam seguir carreiras em setores como engenharia e informática.

Em relação ao ensino superior, ainda que $60 \%$ dos concluintes no Brasil sejam mulheres, em cursos como engenharia, matemática e física essa participação cai para cerca de 40\%. Em relação ao número de matrículas em cursos de graduação, em bacharelado o número de estudantes mulheres, em 2016, foi da ordem de 3.053.794 ao passo que de estudantes homens foi de 2.495.942. Em relação aos cursos de licenciatura essa diferença é proporcionalmente muito maior: foram 1.081 .040 mulheres e 439.454 homens.

Ainda que essas diferenças estatísticas entre homens e mulheres, tanto como discentes quanto como docentes, sejam impactantes, é premente destacar que tais aspectos dizem de construções culturais e políticas e disputas ideológicas em relação ao gênero e não por qualquer razão relacionada a algo que seja "natural" ou "biológico".

É fundamental, então, ressaltar que o termo "natural", comumente empregado ao se falar em sexo e gênero, torna-se especialmente problemático ao reduzir as diferenças entre homens e mulheres ao biológico. Ainda que um discurso essencialista esforce-se para comprovar a ideia de que homens e mulheres seriam tal qual seriam devido a presença de determinado órgão genital ao invés de outro ou devido a quantidade específica de certo hormônio, tal qual pondera Henrietta Moore (1997, p. 01), oblitera-se de uma informação vital: a de que a própria biologia, bem como seu campo de saber, constitui-se não em algo fixo e estável, mas em um "componente dinâmico de nossa existência". 


\section{autêntica}

DOI https://doi.org/10.31639/rbpfp.v12i24.338

Apesar de vender-se como a "expressão instintiva da verdade pré-discursiva da carne" a identidade sexual, na realidade, consiste em "um efeito de reinscrição das práticas de gêneros nos corpos" (PRECIADO, 2014, p. 29).Macho/Fêmea e Masculino/Feminino seriam, pois, categorias que dissimulariam o fato de que as diferenças sociais implicariam uma ordem econômica, política e ideológica (WITTIG, 2010). Butler (2019), a partir desse mesmo lugar, lembrará que o sexo não pode ser tomado como uma descrição estável daquilo que alguém é, mas, ao invés disso, como uma norma pela qual esse alguém é tornado viável.

Ao publicar Gender Trouble, em 1990, Butler, parte do pressuposto de que, tal qual o gênero, o sexo também é uma construção cultural. Butler não se limitou então a radicalizar uma perspectiva antiessencialista, mas, mais do que isso, partindo de uma reconsideração sobre a oposição entre natureza e cultura, ela teria recusado a habitual transposição disso para o sistema sexo/gênero.

Longe de serem substâncias permanentes, portanto, tais categorias teriam a sua coerência e relação estabelecida a fim de garantir a manutenção daquilo que Adrienne Rich (2010) definiu como "heterossexualidade compulsória". "Resulta daí que o gênero não está para a cultura como o sexo está para a natureza; ele também é o meio discursivo/cultural pelo qual a natureza sexuada ou um sexo natural é produzido e estabelecido como pré- discursivo" (BUTLER, 2012, p. 25).

Ainda que construções linguísticas e ideológicas, masculino e feminino são potentes marcadores de identidade e de diferenças e, por conseguinte, no seio de uma sociedade patriarcal, fundadores de desigualdades que são estruturantes.

\section{Supressão e exclusão: o silenciamento do debate sobre gênero como apagamento de direitos}

Remontamos ao trabalho de Jeane Felix (2015) para lembrar alguns dos equívocos existentes na supressão dos conteúdos sobre gênero e sexualidade no texto final do Plano Nacional de Educação. A professora destaca dois pontos em relação ao fato. O primeiro deles a retirada dos conteúdos, resulta do avanço dos conservadores sobre a educação. O segundo se refere à confusa interpretação que estes setores têm do conceito gênero. A tese apresentada e os argumentos utilizados pelos agitadores de gênero nada tem a ver com aquilo que está proposto nos estudos de gênero. Felix sublinha que na conjuntura educacional brasileira, especialmente desde quando foram publicados os Parâmetros Curriculares Nacionais em 1998, os temas ligados ao gênero e à sexualidade seriam abordados pelos currículos da educação básica com o objetivo de mitigar tratamentos desiguais conferidos, historicamente, a meninos e a meninas, a homens e a mulheres. Para tanto, houve um grande investimento proveniente de diversos setoresdesde os governamentais até os acadêmicos, passando pelas organizações não-governamentais, em processos de formação docente, na produção de materiais para essas formações e no estímulo ao desenvolvimento de projetos educacionais que abordassem o tema (FELIX, 2015, p. 225).

Essencializar os sujeitos, negar o gênero é afirmar a exclusão de direitos humanos. Raewyn Connell (2016, p. 60), uma das principais estudiosas das masculinidades, ao ponderar sobre o conceito de gênero o percebe como "uma estrutura de relações sociais na qual as capacidades reprodutivas dos corpos humanos são postas na história e, na qual todos os corpos, férteis ou não, são definidos por sua colocação na arena reprodutiva". Nesse sentido, para a pesquisadora, a maior parte daquilo que ela chama de ordens de gênero (em referência às maneiras de corporificação social dessas normas) seria patriarcal, ou seja, construiria 


\section{autêntica}

DOI https://doi.org/10.31639/rbpfp.v12i24.338

privilégios aos homens (e a determinados homens, mais especificamente), ao passo que subordinaria muIheres (e também outros grupos de homens).

Connell (2016) ressalta que não se pode pensar o gênero como algo isolado, de modo que não haveria apenas uma masculinidade, mas múltiplas, atravessadas por questões como etnia, classe social e orientação sexual. Isso quer dizer que, ao incorporarem a masculinidade e ao se reportarem a ela, diferentes homens o fazem de diferentes modos, a partir de diferentes lugares. Ainda que não se configure como normal em um sentido estatístico, a masculinidade hegemônica é aquela que incorpora a resposta aceita no que se refere à legitimação do patriarcado, garantindo aí a subordinação das mulheres aos homens, bem como de determinados tipos de homens a outros. Outros homens, os quais encarnam masculinidades subordinadas, marginais ou mesmo cúmplices reportam-se de modos absolutamente distintos e colhem dividendos patriarcais que não são os mesmos (CONNELL, 2016).

Nesse mesmo sentido, Miguel Vale de Almeida (1995, p. 17) lembra que a masculinidade corresponde a um "um processo construído, frágil, vigiado, como forma de ascendência social que pretende ser" e que, portanto, em uma lógica binária, ancorada em uma matriz de pensamento que é essencialista, desde o início de suas trajetórias, desde que se declara "é um menino" ou "é uma menina", o corpo então designado passa a poder ocupar determinados espaços ao passo que outros tantos Ihes são negados. E na escola, como discutido, não é diferente.

Conforme lembra leda Silva (2004), que aciona dados clínicos de tratamento psicoterapêutico com sintomas escolares (tais como agressividade, distúrbios no comportamento, hiper-agitação, dificuldadesde concentração e de aprendizagem), especialmente entre crianças com idade entre 8 e 12 anos, o número de meninos atendidos é da ordem de 70\%. E o gênero, mais uma vez, como aponta Silva (2004), materializa-se inclusive nos modos possíveis de se lidar com o problema. Salientando que não deseja assumir uma posição acusatória e/ou generalista, a pesquisadora evidencia como, em muitos casos, a partir de uma visão de mundo que percebe no menino agressivo índices que o relacionam a um homem adulto violento, muitas professoras tendem a assumir posturas de repressão severa e, não esporadicamente, acionar medidas legais para coibir atos que são praticados por crianças. Mais adiante, ao passo que analisa um caso específico, Silva (2004) sugere que, também a partir de uma lógica que é binária e generificada, a escola tende a condenar aquilo que compreende como uma agressividade masculina e valoriza aquilo que toma como uma docilidade feminina, enfatizando, por conseguinte, a perspectiva de que tais características seriam essenciais.

Penso que a escola, na medida em que pode ser representativa das leis simbólicas, do fomento à singularidade na coletividade, da solidariedade entre semelhantes, da intermediação da palavra em situações de atrito, dos espaços alternativos de circulação e convivência, dos contínuos desafios intelectuais e experiências compartilhadas, representa um caldo cultural e afetivo decisivo para a estruturação de muitas crianças, se estiver regida pela ética da diferença (SILVA, 2004, p. 82-83).

Ao considerarmos a escola como espaço para a produção de saberes, lugar de amadurecimento ético, como ocasião favorável ao pensamento crítico, entendemos as razões pelas quais os combatentes do gênero pretendem agenciar os projetos educacionais. A formação continuada é o momento quando docentes podem rever suas práticas, atualizar-se, elaborar novas estratégias de ensino a partir das demandas da comunidade escolar.Retirar os conteúdos que abordam o gênero dos processos de formação é desconsiderar a emergência de um campo tenso e violento, é desconsiderar processos de violência física e simbólica praticadas por corpos conformados por certa masculinidade. Para estes sujeitos, com vistas a manter-se no topo da 


\section{autêntica}

DOI https://doi.org/10.31639/rbpfp.v12i24.338

pirâmide social, é preciso adestrar ou destruir tudo que os ameaça. Uma masculinidade frágil, que reage de modo agressivo sempre que se sente atacado. É preciso entender a necessidade do debate sobre gênero e sexualidade para promover uma educação de qualidade, que promova a igualdade e invista no respeito a todos os corpos e formas de existência. 


\section{autêntica}

DOI https://doi.org/10.31639/rbpfp.v12i24.338

\section{REFERÊNCIAS}

BIROLI, Flávia. Gênero e desigualdades. Limites da democracia no Brasil. São Paulo: Editora Boitempo, 2018.

BUTLER, Judith. Corpos que importam: os limites discursivos do "sexo". São Paulo: n-1, 2019.

BUTLER, Judith. Problemas de gênero: feminismo e subversão da identidade. São Paulo: Editora Record, 2012.

CONNELL, Raewyn; PEARSE, Rebecca. Gênero: uma perspectiva global. São Paulo: Versos, 2015.

CONNELL, Raewyn. Gênero em termos reais. São Paulo: nVersos, 2016.

FELIX, Jeane. Gênero e formação docente: reflexões de uma professora. ESPAÇO DO CURRíCULO, v.8, n.2. Maio a Agosto de 2015. p. 223-231.

JUNQUEIRA, Rogério Diniz. A invenção da "ideologia de gênero": a emergência de um cenário político-discursivo e a elaboração de uma retórica reacionária antigênero. Rev. psicol. polít. [online]. 2018, vol.18, n.43, pp. 449-502.

LOURO, Guacira Lopes. Gênero, sexualidade e educação. Petrópolis: vozes, 1997.

LOURO, Guacira Lopes. Um corpo estranho: ensaios sobre sexualidade e teoria queer. Belo Horizonte: Autêntica Editora, 2008.

MOORE, Henrietta. Compreendendo sexo e gênero. Companion Encyclopedia of Anthropology. London: Routledge, 1997.

PRECIADO, Beatriz. Manifesto contrassexual; tradução de Maria Paula Gurgel Ribeiro. São Paulo: n-1 edições, 2014.

$\mathrm{RICH}$, Adrienne. Heterossexualidade compulsória e existência lésbica. Bagoas Estudos gays: gêneros e sexualidades, v. 4, n. 05, p. 17-44, 2010.

SILVA, leda Prates da. Para ser um guri: espaço e representação da masculinidade na escola. Estilos da Clínica, v. 9, n. 17, p. 70-83, 2004.

VALE DE ALMEIDA, Miguel. Gênero, masculinidade e poder: revendo um caso do sul de Portugal. In: Anuário Antropológico, p. 161-190, 1995.

WITTIG, Monique. El pensamiento heterosexual y otros ensayos, Egales, Barcelona, 2010.

MENDONÇA, C. M. C.; MENDONÇA, F. V. K. M.; Pedagogizar corpos e conformar subjetividades: o sintagma ideologia de gênero como exercício colonizador da educação. Formação Docente - Revista Brasileira de Pesquisa sobre Formação de Professores. Belo Horizonte. Vol. 12, nº 24 (p. 91-104) 31 ago. 2020 